This is the submitted version of the following article: Cerda, AP, et al. Composting of food wastes: status and challenges in Bioresouce technology (Ed. Elsevier), vol. 248, part A (Jan. 2018), p. 57-67, which has been published in final form at

DOI 10.1016/j.biortech.2017.06.133

(c) 2017. This manuscript version is made available under the CC-BY-NC-ND 4.0 license http://creativecommons.org/licenses/by-nc-nd/4.0/ 


\section{Composting of food wastes: Status and challenges}

2

3 Alejandra Cerda, Adriana Artola, Xavier Font, Raquel Barrena, Teresa Gea, and Antoni

4 Sánchez*

5

$6 \quad$ GICOM Research Group

7 Department of Chemical, Biological and Environmental Engineering

8 Escola d'Enginyeria

$9 \quad$ Universitat Autònoma de Barcelona

1008193 Bellaterra (Barcelona, Spain)

11

$12 *$ Corresponding author

13

14 Email: antoni.sanchez@uab.cat

15 Tel.: +34-935811019

16 Fax: +34-935812013

17 


\section{Abstract}

This review analyses the main challenges of the process of food waste

21 composting and examines the crucial aspects related to the quality of the produced

22 compost. Although recent advances have been made in crucial aspects of the process,

23 such composting microbiology, improvements are needed in process monitoring.

24 Therefore, specific problems related to food waste composting, such as the presence of

25 impurities, are thoroughly analysed in this study. In addition, environmental impacts

26 related to food waste composting, such as emissions of greenhouse gases and odours,

27 are discussed. Finally, the use of food waste compost in soil bioremediation is discussed 28 in detail.

29

30 Keywords: composting; food waste; odours; greenhouse gases; microbiology. 


\section{Introduction}

32

Food waste (FW) comprises the main fraction (45\%) of total municipal solid waste in Europe (IPCC, 2006). This percentage averages 55\% in developing countries (Troschinetz and Mihelcic, 2009). Until a few years ago, the final destination of FW was either disposal in landfills or incineration. Although this situation persists in many countries, other nations have considered more sustainable methods for waste management and have developed new legislation regarding the final disposal of solid wastes which involves material valorisation of FW.

Material valorisation is usually conducted by biological processes such as composting and anaerobic digestion. Both processes are based on biological degradation of the organic matter and occur under aerobic and anaerobic conditions, respectively. Compost, an organic amendment, is the final product of the composting process. Biogas, which contains a mixture of gases consisting mainly of methane $\left(\mathrm{CH}_{4}\right)$ and carbon dioxide $\left(\mathrm{CO}_{2}\right)$, and a non-stabilised digestate, are the final products of the anaerobic digestion process. Both processes are an efficient and environmentally friendly alternative for managing FW and are used extensively worldwide. Diverting municipal solid waste organic material from landfills to composting or anaerobic digestion has many environmental benefits. Among them, reduction in landfill emissions of greenhouse gases (GHGs) and improvement of soil properties through compost application have been highlighted (Bernstad et al., 2016). The processes for both cases are well known and have been discussed in recent literature; however, some aspects can be further improved, particularly for FW composting. Thus, this study aims to provide a general overview of the composting of FW by identifying the main challenges occurring in the process. 
Briefly, the production of high-quality compost requires that the process must be properly controlled and managed, as summarised in Figure 1. FW is a highly heterogeneous material with a high moisture content, high organic to ash ratio, and an amorphous physical structure. Moreover, FW can contain a high percentage of inert materials such as glass or plastic depending of the collection system. These particular characteristics will affect some aspects of the process. The $\mathrm{pH}$, carbon to nitrogen ratio $(\mathrm{C} / \mathrm{N})$, moisture content, aeration rate, particle size, and porosity must be properly set considering the characteristics of the FW. Mistakes in the initial preparation and adjustment of the mixture with typical bulking agents or in the control of the process will lead to odour emissions, increases in the environmental impact of the process, and low-quality compost. Determining the compost quality is also a challenge because several methodologies can be used to assess its maturity and stability, particularly in the case of FW, in which inert materials in the compost must be considered. Moreover, the compost quality determines the suitability of further application on soil bioremediation or other applications.

Throughout this review, the main parameters controlling the composting process, including its microbiology and its effect when FW is composted, are discussed. Special attention is given to key parameters such as porosity, the microbiology of the process, respirometric techniques, and stability limits. In addition, compost quality, GHG emissions, and the application of compost in soil bioremediation are also reviewed.

2. General challenges in the composting of food waste

\subsection{Food waste composition}



for several reasons that are related to its inherent heterogeneous composition, high moisture content, and low calorific value, which impede the development of robust, large-scale, and efficient industrial processes (Adhikari et al., 2008). FW can be highly variable depending on its source and is strongly dependent on the eating habits of consumers. Thi et al. (2015) conducted a review that showed FW can comprise $74-90 \%$ moisture, and have a volatile solids to total solids ratio (VS/TS) of $80-97 \%$, and a $\mathrm{C} / \mathrm{N}$ ratio of $14.7-36.4$. Chang and Hsu (2008) developed a method for predicting 10 parameters of the FW composting process including composting and acidification times, highest temperature, final and lowest $\mathrm{pH}$ values, cumulative $\mathrm{CO}_{2}$ evolution, and the percentages of material losses in terms of the weight fractions of protein and fat of synthetic FW composed of human and animal foods. The model proved to be effective for kitchen waste and obtained good predictions. The final products of all experimental runs passed multiple maturity tests. Despite the promising results, their study was performed using synthetic waste; therefore, these results need to be validated with real FW.

The collection and sorting system also influences the FW composition, the composting process and the final product quality because the initial non-organic components in the FW will determine the impurity content at the end of the process. (OFMSW) is a key process because it reduces the non-organic content in biowaste, and thus, the impurities such as heavy metals and pesticides in the compost (Huerta-Pujol et al., 2010). Understanding the factors affecting the presence of non-organic impurities in 
biowaste is required to avoid negative effects such as higher treatment costs, reduced plant capacity, and lower compost quality (Puig-Ventosa et al., 2013). The role of impurities in the composting process will be further discussed in section 5.1.

\subsection{Odours}

Odours are inherent by-products of the composting process regardless of the initial organic material or process condition. Odours clearly contribute to the environmental impact of composting facilities and cause social concern that in many cases results in plant closure or the implementation of prevention measures (Colon et al., 2012). In recent years, great effort has been made in identifying and quantifying the emitted odorants, the major source of which is volatile organic compounds (VOCs) (Maulini-Duran et al., 2014; Scaglia et al., 2011) . It has been reported that VOCs are abundantly emitted when composting the OFMSW which is comprised mainly of FW. A progressive reduction of VOC emission complexity including the amount and diversity occurs throughout the biological process (Scaglia et al., 2011). Although the relative abundance of these pollutants may vary, the most commonly emitted VOC families are terpenes, aliphatic carbons, aromatic hydrocarbons, ketones, and esters (Zhang et al., 2016).

Many other studies that agree with these findings have also identified limonene as one of the most relevant VOCs (Komilis et al., 2004; Wei et al., 2017). Komilis et al. (2004) determined that for FW, the most abundant families of VOC emitted were sulphides, acids, and alcohols; xenobiotic VOCs occurred to a lesser extent. Their presence is likely a result of various reactions that take place during the cooking of some food constituents owing to small amounts of pesticides present on raw vegetables or merely a result of atmospheric deposition. 
Maulini-Durán et al. (2015) identified dimethyl sulphide, dimethyl disulphide, limonene, and $\alpha$ and $\beta$-pinene as the most significant odorous VOCs in a composting process of OFMSW. According to their study, the latter two compounds were mainly released from the wood chips used as bulking agent (BA).

Considering odours derived from nitrogen compounds, the most important pollutant generated in FW composting is ammonia $\left(\mathrm{NH}_{3}\right)$, its release favoured by the low $\mathrm{C} / \mathrm{N}$ ratio of $\mathrm{FW}$ (Zang et al., 2016). The release of $\mathrm{NH}_{3}$ is strongly dependent on the $\mathrm{pH}$ and temperature of the composting pile and is favoured by high temperatures (thermophilic) and alkaline conditions (Pagans et al., 2006). Another nitrogen-derived odour reported to be produced in FW composting is trimethylamine, which is normally produced in industrial-scale FW treatment plants (Wei et al., 2017). This compound is important because it has a low odour threshold, which implies a substantial contribution to odorous pollution (Tsai et al., 2008).

Odours derived from sulphur have also been reported during the composting of FW, including dimethyl sulphide, dimethyl disulphide, and methyl mercaptan (Komilis et al., 2004; Maulini-Duran et al., 2014; Zhang et al., 2016) . There is no clear predominant pollutant among the studies reported, which is likely associated with the fact that sulphur compounds are generated mainly from the biodegradation of sulphurcontaining proteins during composting (Komilis et al., 2004). The characteristics of the raw material are of great importance, particularly in FW. Another factor that could explain the differences for all odours in addition to those from sulphur-derived compounds is that the temperature and aeration rate can affect the microbiota development during the process (Zhang et al., 2016).

The relative abundance of odorous compounds is dependent on the starting material, configuration of the composting process (i.e. open or closed), and process 
conditions such as moisture and aeration, as well as the composting stage (i.e. active composting phase or curing phase) and composting operations (e.g. shredding, screening, or turning).

In order to mitigate the emission of these pollutants, it is necessary to optimise the composting process by i) maintaining the proper aeration rate and thus avoiding anaerobic conditions in the solid composting matrix and ii) selecting different BAs in an adequate ratio to provide the required free air space. A novel method for optimising biological activity using the oxygen uptake rate (OUR), which has been proposed by Puyuelo et al. (2010) and assessed by Maulini et al. (2014), has shown a slight reduction in VOC generation.

Finally, the incorporation of gas treatment units in composting installations must be considered. Biofiltration is a common treatment in composting facilities which can aid in the reduction of gaseous compounds and odours commonly encountered during the process (Pagans et al., 2006).

\subsection{Process monitoring challenges}

\subsubsection{Routine variables}

The effectiveness of the composting process is influenced by factors such as temperature, oxygen $\left(\mathrm{O}_{2}\right)$ supply (i.e. aeration), moisture content, $\mathrm{pH}, \mathrm{C} / \mathrm{N}$ ratio, particle size, and degree of compaction (Li et al., 2013).

Proper $\mathrm{O}_{2}$ supply is the most important aspect to consider in composting; therefore, aeration is critical. The efficiency of the composting process is strongly affected by $\mathrm{O}_{2}$ level because the composting process is directly associated with microbial population dynamics (Nakasaki and Hirai, 2017). In this sense, the aeration rate affects the quality of the compost and microbial activity in the composting process. 
Rasapoor et al. (2016) compared different aeration systems on FW composting. Both forced aeration and pile turning are shown to be efficient in terms of final compost quality, although the latter showed better results for agricultural applications even though it was associated with significant energy consumption and pollutant emissions. Additionally, Guo et al. (2012) proved that a low aeration rate $\left(<0.2 \mathrm{~L} \mathrm{~min}^{-1} \mathrm{~kg}^{-1} \mathrm{OM}\right)$ led to a low degradation rate, moisture and heat loss, reduction in the overall $\mathrm{NH}_{3}$ generation, and significant decrease in temperature, therefore affecting microbial diversity. Adequate aeration rates, ranging from 0.2 to $0.6 \mathrm{~L} \mathrm{~min}^{-1} \mathrm{~kg}^{-1} \mathrm{OM}$, show significant improvements in $\mathrm{NH}_{3}$ and odour release, $\mathrm{C} / \mathrm{N}$ ratio reduction, and compost maturity (Zhang et al., 2016; Zhang and Sun, 2016). These authors also concluded that aeration is the main factor affecting compost stability, whereas the $\mathrm{C} / \mathrm{N}$ ratio influenced compost maturity. These facts were also observed by Wang et al. (2016), who reported no significant differences when assessing different $\mathrm{C} / \mathrm{N}$ ratios in $\mathrm{FW}$ composting. A statistical approach has been undertaken by Li et al. (2015) to assess the most influential parameter on the final product maturity in FW composting. It was stated that all the parameters influence composting maturity; however, the aeration rate proved to have a more significant effect, which is in accordance with the results reported by other authors (Nair and Okamitsu, 2010).

The $\mathrm{C} / \mathrm{N}$ ratio is important for several aspects of composting but is particularly crucial for the development of microorganisms during composting because it provides the carbon and nitrogen source required for growth. Limiting the content of $\mathrm{N}$ is undesirable because it generates a reduction in the $\mathrm{C}$ consumption rate, whereas an excess in $\mathrm{N}$ can generate the release of $\mathrm{NH}_{3}$ gas (Zhang et al., 2016). In this sense, the $\mathrm{C} / \mathrm{N}$ ratio is a measure of the decomposition degree owing to the degradation of carbon to $\mathrm{CO}_{2}$ during the high-rate degradation stage. Then, the $\mathrm{C} / \mathrm{N}$ ratio decreases throughout 
the composting process as reported by Yang et al. (2015) and Wang et al. (2016) because the $\mathrm{C}$ degradation rate is higher than the mineralisation rate of $\mathrm{N}$. Thus, an excessive $\mathrm{C} / \mathrm{N}$ relates to a deficiency of nutrients to microbiota, and a low $\mathrm{C} / \mathrm{N}$ ratio implies the release of several undesirable compounds such as odours or salts, which are unfavourable for plant growth (Onwosi et al., 2017). The recommended initial $\mathrm{C} / \mathrm{N}$ ratio at the start of the composting process ranges from 25-30. However, many other authors have used a different $\mathrm{C} / \mathrm{N}$ ratios, between 20-40 (Maulini-Duran et al., 2014; Yang et al., 2015), with good results. Although the extended use of this ratio, it is important to note that FW can present slow or non-biodegradable carbon sources depending on the presence of impurities such as plastics, textiles, wood, etc. In this sense, the use of a ratio based on the biodegradable organic carbon should be more adequate (Puyuelo et al., 2011).

Particle size is an important parameter in FW composting, although it is not often measured. This parameter influences the setting of the porosity level for proper aeration (Ruggieri et al., 2009) and determines the water-holding capacity and gas/water exchange in the final compost (Zhang and Sun, 2016). Particle size may not be the most important parameter for composting, but it is related to the porosity, which is the greatest challenge to overcome when using FW as raw material.

\subsubsection{Mixture conditioning: porosity as the main challenge}

One of the most important properties in the composting of FW is porosity (Ruggieri et al., 2009), which is influenced by several parameters such as particle size and moisture content clearly influencing $\mathrm{O}_{2}$ content. These parameters determine the performance of the composting process. For example, in FW, the water content is normally high (Adhikari et al., 2008); therefore, if the porosity is not adequate, the pore 
spaces could be filled with water, which could lead to the generation of anaerobic zones and consequently to odour release. Achieving proper porosity levels ensures correct air circulation through the solid matrix and provides full aerobic conditions, thereby achieving the correct proliferation of microorganisms. In addition, if the air flow provided to the mixture is adequate, the processes of $\mathrm{CO}_{2}$ and heat removal and the regulation of the water content are promoted.

As previously stated, it is highly recommended to work under optimum porosity levels in order to achieve the desired composting conditions. Different approaches have been used to measure the porosity of a mixture; however, the most utilised and reliable measure is FAS (free air space) determination (Su et al., 2006, Ruggieri et al., 2009). In addition, FAS is often calculated by means of a theoretical and empirical formula which considers bulk density and other parameters such as particle size or the dry or organic mass content (Soares et al., 2013, Ruggieri et al., 2009).

Despite the high importance of porosity in FW composting, most recent studies did not adjust the porosity in their respective mixtures. In such works, a tangential approach to the subject is shown which considers only BA incorporation to adjust the moisture and the $\mathrm{C} / \mathrm{N}$ ratio (Külcü, 2015; Mu et al., 2017). In FW composting, several BAs have been evaluated. Among them, cereal residue pellets and wood chips have resulted in better conditions for FW composting even considering variations in the physical composition (Adhikari et al., 2008; Schwalb et al., 2011). Most of these studies reported an adequate FAS range of 30-50\% for FW composting (Hong et al., 2012; Schwalb et al., 2011; Soares et al., 2013; Su et al., 2006; Yu et al., 2009); however, it was not specified whether those values are initial or were maintained during the entire composting process. In this sense, almost no literature is available on the FAS conditions in the curing stage. Yu et al. (2009) assessed the effect of FAS during the 
curing stage by using passive aeration reporting values up to $67 \%$ as a proper curing stage value. Neglecting the study of this stage could limit the understanding of the entire process and could have an impact on the quality of the compost.

In addition to the well-known effects of porosity on the performance of the composting process, Külcü (2015) assessed the relationship between appropriate FAS values and the energy consumption of the composting process of chicken manure. This author found an optimum FAS range of $30-33 \%$, which is in accordance with many studies (Ruggieri et al., 2009). However, the author also reported that working below $30 \%$ resulted in a 30\% increase in the energy consumption. Despite this result, the overall composting process was not negatively affected likely because the high clearance volume creates an increase in the heat transfer, which in turn decreases the mass temperature.

\subsubsection{Process control parameters}

Properties such as cation exchange capacity, $\mathrm{C}: \mathrm{N}$ ratio, and humic fraction ratio have traditionally been used for the monitoring of composting processes. However, biological and biochemical parameters have recently arisen as good indicators both during and at the end of the aerobic biotransformation of organic waste (Barrena et al., 2009). Biological methods for monitoring the composting process are based on the respiration index (RI) of the biomass under dynamic (DRI) and static conditions (SRI) (Barrena et al., 2009; Barrena et al., 2006). Both parameters are indicators of the biological activity of a composting process but provide only quantitative results when they are employed in identical conditions, which is not always feasible. Ideally, both indices would be identical in an aerobic environment; however, significant differences have been found between both indices in composting experiments. Concretely, the use 
of SRI resulted in an underestimation of the biological activity of a compost sample, which is usually attributed to $\mathrm{O}_{2}$ diffusion problems in the determination of the respirometric index in solid static samples. These issues were resolved when using continuous aeration in the solid matrix (Barrena et al., 2009).

\section{Microbiology in food waste composting}

The composting process is conducted in a series of different microorganisms aiming to degrade organic matter. Therefore, the monitoring of these microorganisms in succession is key for effective management of the composting process, rate of biodegradation, and compost quality given that the appearance of some microorganisms reflects the maturity of the compost (Jurado et al., 2014).

\subsection{New analytical tools}

Numerous techniques have been used for investigating the change in the microorganism diversity during the composting process. These methods can be classified as culture-based or culture-independent methods. Among the culture-based methods, different techniques have been proposed such as measurement of the adenosine triphosphate (ATP) content (Horiuchi et al., 2003), microbial activity (Ryckeboer et al., 2003) and potential metabolic abilities determined by the BIOLOG sole-carbon utilisation test (Borrero et al., 2006).

Horiuchi et al. (2003) performed ATP measurement in compost, which enabled the monitoring of microbial activity of the composting process at a lab scale. The analytical simplicity of the method makes it an attractive alternative for the monitoring of a large-scale process. Despite the effectiveness of the aforementioned methods, all of them use isolated strains able to grow in specific solid matrices (agar in Petri dishes). 
However, they can provide a restricted overview of the microbiome during the composting process. This is possible because only $<1 \%$ of the total DNA in complex samples such as compost correspond to culturable microorganisms; therefore, more than $99 \%$ of the microorganisms remain viable but not culturable. These organisms could represent completely novel groups and may be abundant or very active but remain untapped by standard culture methods. For this reason, different culture-independent methods have been developed that enable identification of microbial communities without the culturing of organisms on agar media. Among them, the direct analysis of phospholipid fatty acid (PLFA) patterns (Amir et al., 2010; Carpenter-Boggs et al., 1998) or, more interestingly, the use of molecular tools on extractable DNA or RNA in compost samples is attractive (Jurado et al., 2014). The assessment of microbial communities using both a classical approach (culturing) and a molecular approach (16S rDNA analyses) led to different and sometimes contradictory results (Ishii and Takii, 2003).

The use of novel techniques is certain to help the detection of unique microorganisms; however, they still present many uncertainties. Consequently, traditional methodologies are still useful in environmental microbiology. Tiquia (2010) combined traditional plating techniques with terminal restriction fragment length polymorphism analysis (T-RFLP) to monitor changes in bacterial and fungal community composition during composting, and Antunes et al. (2016) combined several molecular biology techniques. Furthermore, each technique appears to have its own limitations. For example, only a few PLFAs can be considered to be absolute signature substances for a single species or even a specific group of organisms (Carpenter-Boggs et al., 1998). However, analyses of DNA or rRNA followed by 16S (prokaryotes) or 18S (eukaryotes) analyses do not always reflect the qualitative and 
quantitative diversity present in environmental samples such as compost because some DNA may be recalcitrant for extraction in these types of samples (Jurado et al., 2014). In addition, Franke-Whittle et al. (2005) developed a microarray consisting of oligonucleotide probes targeting variable regions of the 16S rRNA gene, which enabled identification of different microorganisms. Even though this technique is simple to assess, it requires the full sequence of one target microorganism in order to confirm its presence in the sample. Therefore, this method is suitable only for confirming a normally found strain but not for identifying new species. Therefore, culture-based and culture-independent molecular techniques are neither contradictory nor exclusionary and should be considered as complementary.

In light of all the different new techniques, Antunes et al. (2016) approached the identification of a microbiome in the thermophilic stage of composting by using a combination of different techniques using shotgun DNA, 16S rRNA gene amplicon, and metatranscriptome high-throughput sequencing. This enabled an unprecedented clone libraries but not from community fingerprint data (Bent and Forney, 2008).

\subsection{Microbial communities}

Along with the development of new molecular biology tools, new research with 
microbiome during the different stages of the composting process. Normally, microbiome identification is conducted in order to fully understand the composting process itself (Franke-Whittle et al., 2014; López-González et al., 2015); however, more specific goals are being developed.

Wang et al. (2017) reported that the dominant phyla of the community structure in fed-batch composting were Firmicutes, Proteobacteria, Bacteroidetes, and Actinobacteria as determined by high-throughput sequencing. In this study, the authors also reported higher diversity in the maturation phase compared with that in the thermophilic biodegradation stage. During the last decades, a large variety of mesophilic, thermotolerant, and thermophilic aerobic microorganisms including bacteria, actinomycetes, yeasts, and various other fungi have been extensively reported in composts (Antunes et al., 2016; Franke-Whittle et al., 2014; Ishii and Takii, 2003; Kinet et al., 2015; López-González et al., 2015). A list/summary of some of the microorganisms identified during FW composting is presented in Table 1. Successful composting depends on a number of factors that have both direct and indirect influences on the activities of the microorganisms (Chandna et al., 2013).

Composting is a process performed by a series of microorganisms associated with different degradation systems (López-González et al., 2015). Several authors have focused their research on the study of the lignocellulosic fraction of FW because the microorganisms able to degrade this fraction play important roles in the successful operation of composting (Franke-Whittle et al., 2014; López-González et al., 2015). Generally, most of the biological diversity occurs in the high-rate degradation stage and is related to the highest lignocellulosic enzymatic activity, which results in a proper composting process (Chandna et al., 2013; López-González et al., 2015). Despite the fact that the information, including both culture-dependent and non-culture-dependent 
methods, facilitates microbiome assessment, the technology still suffers from many drawbacks, resulting in significant differences among studies. In this sense, Antunes et al. (2016) monitored the microbial succession in FW composting by using different molecular biology tools. They reported that turning of the pile during the high-rate degradation stage is the key for maintaining the microbial diversity and to a certain extent the population profile present at the beginning of the process. Additionally, lignocellulosic biomass deconstruction occurs synergistically and sequentially, with hemicellulose being degraded preferentially to cellulose and lignin. This information provides a complete vision of the process with a great potential for new sources of research. In this case, metagenomic and metatranscriptomic approaches were successfully applied for identification and to fully understand their active functional metabolic potential during every step of the composting process.

One of the main issues in FW composting is to have a homogenous and representative sample at full-scale facilities, which is often quite small in comparison with large- or even pilot-scale composting reactors. In addition, the operational parameters are responsible for the microbial fluctuations that will or will not be able to thrive at all stages of the process. In this sense, the composting microbiota act on a succession of different microorganisms that are strongly dependent on each other and are conditioned by biotic and abiotic factors (López-González et al., 2015).

Another issue in working with FW is the gaseous emissions and odour generation. For this reason, some authors use assessment of microbial communities as a tool to correlate the changes in operational parameters such as $\mathrm{pH}$ with the microbial communities and their effect on odour generation. Sundberg et al. (2013) reported a high abundance of acid-producing bacteria and fungi which led to a $\mathrm{pH}$ drop and the consequent increase in odour generation. This study helped develop an important 
strategy for reducing odour from FW composting, namely rapidly overcoming the initial

407 low-pH phase. This can be achieved by a combination of high aeration rates that

408

409

410

411

412

413

414

415

416

417

418

419

420

421

422

423

424

425

426

427

428

429

430

provide $\mathrm{O}_{2}$, and cooling and application of additives such as recycled compost. Shi et al. (2016) assessed the dynamics of $\mathrm{NH}_{3}$-oxidising bacteria (AOB) populations in $\mathrm{FW}$ composting. These microorganisms play a fundamental role in the $\mathrm{N}$ cycle, and thus in the $\mathrm{NH}_{3}$ concentration and emissions, during the process. They demonstrated that both $\mathrm{pH}$ and nitrate are related to the $\mathrm{AOB}$ community composition.

A different approach was taken by Hou et al. (2017) and Xie et al. (2017), who assessed the effect of adding psychrotrophic bacteria to the composting of FW and its effect on the start-up of the process at low temperatures. In this sense, these authors used the information on the microorganisms to optimise the entire process, which significantly reduced the overall process time and enabled correct composting even during the winter.

It is widely known that the high microbiome richness and diversity inherent during the composting process changes according to the different environmental process conditions. These facts have led some authors to select a consortia of microorganisms of interest to further be used in industrial applications aimed towards a microbial resource management approach (Kinet et al., 2015).

\subsection{Inoculation needs}

Despite the fact that composting is a naturally developing process, it has been reported that the addition of inoculating agents can result in enhancement of the organic matter degradation rate (Karnchanawong and Nissaikla, 2014; Onwosi et al., 2017).

These inoculants can be a specific strain (Hou et al., 2017; Nakasaki and Hirai; Tsai et al., 2007; Zhao et al., 2016), a commercialised mix of several species (Fan et al.; Ke et 
432 (Karnchanawong and Nissaikla, 2014; Kinet et al., 2015). In most cases, the studies revealed a significant reduction in the operation time of the composting process.

Generally, higher temperatures were achieved, and a reduction in odour was observed. In addition, even the compost quality can be improved. However, other studies show different results. Karnchanawong and Nissaikla (2014) revealed that it might not be necessary to add commercial inoculants to improve the composting of organic waste owing to the slight improvement in the time and quality of the final compost. Moreover, they proved that the addition of mature compost as a starter generated greater improvements in the finished compost in comparison to the use of commercial inoculants. It has been well established that microbiome development during the composting process depends highly on the type of substrate and BA in addition to the environmental conditions and their interactions; therefore, the results obtained in this study cannot be extrapolated to other studies. In this context, Ke et al. (2010) showed that the inoculation of the thermotolerant lipolytic actinomycete Thermomycetes vulgaris $\mathrm{A} 31$ to $\mathrm{FW}$ with a high fat content resulted in a decrease in the composting

447 time and a strong improvement in the compost quality. The characteristics of the substrate determined the type of inoculum and therefore yielded excellent results. Another report by Nakasaki and Hirai (2017) used the acid-consuming yeast Pichia kudriavzevii RB1 as inoculum for FW composting, which showed elimination of the lag 451 phase and stimulation of the microbiota; however, it did not affect the final quality of 452 the final compost. To the contrary, Ding et al. (2016) successfully avoided acidification in the initial stage of FW composting by the inoculation of anti-acidification microorganisms of a bacteria consortium including pseudomonas, bacillus, 
455 lactobacillus, and others. This strategy resulted in compost of higher quality with a

456 higher humic acid content than the control.

457 Considering the lignocellulosic fraction of the FW, some authors have used

458 lignocellulosic microorganisms to improve the lignocellulose degradation (Jurado et al.,

459 2014; Nair and Okamitsu, 2010; Wang et al., 2011; Zeng et al., 2010; Zhao et al., 2016).

460 Most of these studies used an improved composting process with a high-quality final

461 compost; however, not all the results were successful. Nair and Okamitsu (2010)

462 reported that inoculation with lignocellulosic microbiota was not effective in the

463 composting of kitchen waste on a small scale; no significant differences were observed

464 with the control (without inoculation).

465 As mentioned before, the use of a microbial consortium instead of specific or specialised strains may enhance the process performance and compost quality. Manu et al. (2017) reported that several benefits were obtained by using a commercially available inoculum containing lactic acid bacteria, yeast, and phototrophic bacteria. A reduction in process time, enhancement of lignocellulose degradation, and improvement in compost quality were achieved with increased humic and fulvic acids.

The studies conducted on the suitability of different inoculants are inconclusive and scarce, which is likely associated with the complex process of composting and the complex nature of not only FW but organic waste in general.

\section{Gaseous emissions}

Owing to the importance of the subject, extensive research has been performed

477 to determine the environmental impact of FW composting, with many recent reviews

478 and original research papers addressing this issue (Bernstad et al., 2016; Boldrin et al.,

479 2009; Colon et al., 2012; Mu et al., 2017; Nasini et al., 2016). 
A large amount of literature is available on the composting process with the

481

482

483

484

485

486

487

488

489

490

491

492

493

494

495

496

497

498

499

500

501

502

503

504

main aim of improving the production and quality of the finished product. However, such research often neglects the contribution of the process to GHG emissions (Lou and Nair, 2009). In recent years, this subject has been under intensive research (Boldrin et al., 2009; Colon et al., 2012; Lou and Nair, 2009; Maulini-Duran et al., 2014; Nasini et al., 2016; Yuan et al., 2015; Zhang et al., 2016) and normally focuses on the measurements of $\mathrm{NH}_{3}$, hydrogen sulphide, and VOC emissions, which are directly associated with degradation of the organic matter and are responsible for unpleasant odours, as described in Section 2.2. Additionally, nitrous oxide $\left(\mathrm{N}_{2} \mathrm{O}\right)$ and $\mathrm{CH}_{4}$ are often measured. These pollutants are associated with the presence of anaerobic/anoxic zones inside the solid matrix and possess an atmosphere-warming potential 296 and 25 times greater than $\mathrm{CO}_{2}$, respectively (Nasini et al., 2016).

$\mathrm{NH}_{3}$ is often not considered as a GHG; however, it is included in environmental studies because of its role in acid rain and in nitrogen conservation for potential utilisation of compost on soil. $\mathrm{NH}_{3}$ emissions are affected by the $\mathrm{C} / \mathrm{N}$ ratio of the initial composting mixture, the temperature reached during the process, and the aeration pattern (Pagans et al., 2006). $\mathrm{NH}_{3}$ emissions from the OFMSW have been reported to be produced in the thermophilic stage of the composting process at a range of $0.34-8.63 \mathrm{~kg}$ $\mathrm{NH}_{3} \mathrm{t}^{-1}$ waste (Colon et al., 2012; Maulini-Duran et al., 2014; Pagans et al., 2006). The review of different emission factors showed significant differences among the results obtained. For example, for $\mathrm{CH}_{4}$ emissions, a range of $0.03-71.4 \mathrm{~kg} \mathrm{t}^{-1} \mathrm{FW}$ has been reported (Bernstad et al., 2016; Boldrin et al., 2009; Mu et al., 2017; Nasini et al., 2016; Rasapoor et al., 2016). These differences can be attributed to the heterogeneity of the FW and the changing conditions of the reported processes. In this sense, FW normally has a high moisture content, high bulk density, and low $\mathrm{C} / \mathrm{N}$ ratio, 
which are related to GHG emissions. If the FAS is low, the excess of water can create anaerobic zones which promote $\mathrm{CH}_{4}$ production. Proper FAS enables adequate airflow through the solid matrix, preventing $\mathrm{CH}_{4}$ production (Ruggieri et al., 2009).

Additionally, these differences can be attributed to the unclear assumptions on the composting process when using a theoretical approach (Lou and Nair, 2009). In the same context, the GHG emission potential obtained from actual practical data could range from 0.2 to $193.2 \mathrm{t} \mathrm{CO}_{2} \mathrm{eq} \mathrm{t}^{-1} \mathrm{FW}$. These values are lower than those predicted from theoretical calculation, thereby suggesting an overestimation of the theoretical contribution of composting to atmosphere warming.

VOC emissions are composed mainly of compounds such as ketones, sulphides, aromatic compounds, esters, hydrocarbons, and alcohols (Boldrin et al., 2009). The characterisation of these VOC has been the main objective of different studies (Colon et al., 2012; Maulini-Duran et al., 2014). Maulini-Duran et al. (2014) presented a very interesting approach in the composting of the OFMSW in which different BAs were used for evaluating their influence on the stability of the final compost and the effect on gaseous emissions. They found that when using an inert BA such as a plastic pipe, the emissions of $\mathrm{CH}_{4}, \mathrm{NH}_{3}$, VOCs, and nitrous oxide $\left(\mathrm{N}_{2} \mathrm{O}\right)$ generated by the system were lower than those emitted when using a woody BA. However, the use of the latter showed the best results in the stability and quality of the final product. Among the VOC, the predominant family emitted was terpenes with alpha and beta pinene as the most abundant compounds; this was particularly high for the experiment using wood chips as the BA. Komilis et al. (2004) identified the main VOC emitted during the composting of pruning residues, which were mainly terpenes, alkyl benzenes, ketones, and alkanes, and during the composting of FW, which were sulphides, organic acids, and alcohols, as well as during the stages of the process that generated the highest 
emissions, the thermophilic phase. These results are in accordance with those observed by Maulini-Duran et al. (2014).

Despite the GHG generation, the diversion of FW from landfills can help mitigate the overall GHG of this waste disposal option. Moreover, other GHG emissions associated with composting are avoided in the potential application of compost in soils according to reviews and summaries in papers published by Bernstad et al. (2016) and Lou and Nair (2009). These include i) the reduction of GHG emissions from the fossil fuel associated with the production and application of other soil amendments; ii) an increase in $\mathrm{C}$ uptake from plants in the form of $\mathrm{C}$ sequestration of nearly $50 \mathrm{~kg}$ of $\mathrm{C}\left(183 \mathrm{~kg} \mathrm{CO}_{2}\right)$, which could be relevant on a large scale; and iii) improvement in the tillage and workability of soil, thereby reducing emissions from fossil fuels that would otherwise be worked into the soil.

\section{Compost quality}

\subsection{Heavy metals and non-organic content}

The use of compost derived from the organic fraction of municipal waste as a soil conditioner or fertiliser is a sustainable practice for FW recycling which profits from the nutrients present in the compost (Sax et al., 2017). Compost quality is an important aspect regarding the confidence of compost users. One of the main concerns when using food-derived compost is loading the soil with metals that can result in an increased metal content in the crops (Hargreaves et al., 2008). The FW metal content depends strongly on the impurities present in the feedstock. Furthermore, in some cases, metals and excess nutrients can move through the soil into the groundwater. In addition, FW compost has been reported to have high salt concentrations, which can inhibit plant growth and negatively affect the soil structure (Hargreaves et al., 2008). However, the 
magnitude of these negative effects depends on compost properties such as salinity, heavy metal content, and the presence of other impurities such as glass which are not modified during the composting progress (Sharifi and Renella, 2015). In fact, this research proved that it is feasible to improve the quality of compost application on soil by grinding the compost to a particle size of more than $0.8 \mathrm{~mm}$ without significant reduction in the fertilising value of the compost. This is accordance with the findings of He et al. (1995), who stated that most of the heavy metal content comprised particles smaller than $0.8 \mathrm{~mm}$, whereas larger particles were nearly free of $\mathrm{Pb}, \mathrm{Cu}, \mathrm{Cd}, \mathrm{Cr}$, and Ni. Thus, controlled grinding and sieving are feasible alternatives for removing impurities from compost. However, it is important to highlight the importance of the separation source in the quality of the organic matter. In that sense, Huerta-Pujol et al. (2011) observed that the organic fraction obtained from source-sorted collection is more appropriate for composting than that mechanically separated from mass-collected municipal solid waste.

In addition to the effects on the physical characteristics of the soil, a few reports focus on the impact of heavy metals on the soil microbiome. Gomes et al. (2010) concluded that incorporation of $\mathrm{Cd}$ and $\mathrm{Zn}$ into soils can have both short- and long-term effects on various bacterial phylogenetic groups, although the metals may be better tolerated by the dominant soil fungi.

Macroscopic impurities in compost, particularly plastic, glass and metal objects, not only reduce the aesthetic value of land but are also related to accident risk such as work injuries sustained while handling compost containing glass fragments. When compost is used as a component in growing media, direct health and safety aspects are of special importance because of the often quite intense contact workers have with the 
material. Macroscopic glass fragments, for example, must not be present (Sharifi and Renella, 2015).

Additionally, the available information regarding the effects of organic and inorganic compounds present in compost on soil presents considerable discrepancies when the source of the compost is considered. A number of causes may explain the lack of scientific data on organic pollutants. Some researchers have suggested that organic pollutants are of little concern in compost owing to the nature of the source of the separated biowaste (Huerta-Pujol et al., 2010). Other experts suggested that chemical analytical developments in the trace-level detection of organic pollutants combined with heightened awareness of their possible effects have led to the relatively recent discussion of organic pollutants (Hargreaves et al., 2008). This clearly contrasts with the longstanding knowledge of heavy metals and physical impurities (Gomes et al., 2010; Huerta-Pujol et al., 2011; Wei et al., 2017; Zhou et al., 2017).

\subsection{Maturity and stability}

Maturity and stability are important parameters for compost quality assessment. Maturity is a generic term describing the suitability of a compost for a particular use and is commonly associated with plant growth or phytotoxicity. Stability is a term related to the degree of decomposition of biodegradable organic matter contained in a matrix and is indirectly related to the biological activity of a sample (Barrena et al., 2006). As stated by Oviedo-Ocaña et al. (2015) it is easy to assume that these parameters are somehow correlated because phytotoxic compounds are products of the microbial activity of unstable organic matter (Komilis and Tziouvaras, 2009). However, when these authors assessed the maturity and stability of different compost, they observed that stability alone is not sufficient for ensuring high compost quality and that germination 
604

605

606

607

608

indices are highly dependent on the type of seed assayed. In this sense, the simultaneous use of maturity and stability indices is shown as the most suitable parameter for compost quality assessment. In addition, no universally accepted parameters for maturity and stability determination have been reported (Barrena et al., 2006).

Moreover, the threshold values of organic amendment may not be suitable for all composts owing to differences in the origin feedstock as well as the specific conditions of the composting process.

In summary, maturity is not described by a single property and is therefore best assessed by measuring two or more parameters of compost including the stability. Some immature composts may contain high amounts of free $\mathrm{NH}_{3}$, certain organic acids, or other water-soluble compounds which can limit seed germination and root development; therefore, many maturity indices are based on these characteristics (Table 2). All uses of compost require a mature product free of these potentially phytotoxic components. The lack of universally accepted maturity and stability indices have generated a wide variety of innovative techniques for assessing maturity and stability, as summarised in Table 2. For example, Young et al. (2016) recently proposed two new phytotoxicity indices. Both were successful with positive correlations among ecotoxicological tools, biological stability, and physicochemical parameters. These indices could be implemented as monitoring indicators or can even be used as ecotoxicological tools.

One of the most important methods for determining stability is the use of respirometric techniques measuring $\mathrm{CO}_{2}$ production and consumption, or heat production (Barrena et al., 2006; Komilis and Kletsas, 2012). The basis of these methods is that non-stable compost has a strong demand for $\mathrm{O}_{2}$ and high $\mathrm{CO}_{2}$ production rates owing to the intense development of microorganisms as a consequence 
of degradation of the easily biodegradable compounds in raw materials. Therefore, it is a direct measure of microbial activity in any part of the process. The self-heating test is easy to use, but it cannot be directly correlated to respiration indices because many chemical and biochemical reactions not related to respiration are also exothermal. Methods based on $\mathrm{O}_{2}$ consumption are classified as static or dynamic because the assay is made in the absence or presence of continuous aeration; therefore, they can be performed under solid or liquid conditions (Barrena et al., 2006). In addition, the methodologies used in respirometric assays differ in temperature and the amount of sample used. It is considered that respirometric activities measured at fixed temperatures $\left(35-37^{\circ} \mathrm{C}\right)$ are good indicators of the mean metabolic potential of the compost. Liwarska-Bizujojc et al. (2003), through an elemental analysis, observed that the optimum temperature for biodegradation of the OFMSW was at $37^{\circ} \mathrm{C}$ (mesophilic range). Nevertheless, composting is a complex process in which the rate of degradation is a result of the metabolic activity from a mixed microbial population that includes microorganisms with different optimum growth temperatures.

Although these new indices are interesting, respirometric indices are the most reliable and widely accepted measure of stability. The most recognised respirometric indices are the dynamic respiration index (DRI) and the cumulative $\mathrm{O}_{2}$ consumption at four days $\left(\mathrm{AT}_{4}\right)$ (Barrena et al., 2006). These indices have been widely used as stability indicators in several studies at the small and large scale with excellent results (Barrena et al., 2006, Maulini-Duran et al., 2014; Colon et al., 2010; Colon et al., 2017). Moreover, they are also effective for monitoring large-scale composting processes (Colon et al., 2017).

\section{Compost in soil bioremediation}


fertilisers. In this case, the conversion should be performed by implementation of novel technologies for the recycling of waste in the form of compost for their use in agriculture (Vandecasteele et al., 2016). Compost has the benefit of using biomass that might otherwise be landfilled and provides a balance of nutrients in a low-cost amendment. Additionally, the ability of compost to sequester carbon has been highlighted, thereby mitigating climate change (Lehmann and Joseph, 2009). However, the use of compost has two main constrains: the long time required to properly produce mature compost and the space requirements for this process (Safaei Khorram et al., 2016).

Compost, which is derived from FW, has been widely studied for soil remediation in recent years and has been identified as the cheapest and most suitable material for in situ heavy metal removal (Zhou et al., 2017), immobilisation of pesticides (Morillo and Villaverde, 2017), and removal of emerging pollutants (Kuppusami et al., 2017). All the aforementioned research concluded that the effectiveness of compost addition to soil is either dependent on the adsorption by organic matter or is reliant on the degradation by microbes and enzymes (Kuppusami et al., 2017; Morillo and Villaverde, 2017; Zhou et al., 2017). some authors have analysed the effect of a joint addition of biochar along with compost 674 derived from FW. The results indicate improved bulk density and increases in active 675 carbon and potential nitrogen mineralisation compared with unamended soil (Sax et al., 676 2017). For these reasons, some authors have developed systems that obtain a compost677 like biochar (Agegnehu et al., 2016) or work with mixed mature compost with biochar added to the soil (Agegnehu et al., 2016; Bielská et al., 2017). Bielská et al. (2017) 
679 showed that the joint use of compost and biochar was successful in the sorption of

680

681

682

683

684

685

686

687

688

689

690

691

692

693

694

695

696

697

698

699

700

701

pyrene from contaminated soils and promoted the development of a model nematode. In some cases, biochar has been proposed as a co-substrate for the composting process itself of FW or agricultural residues (Khan et al., 2016; Vandecasteele et al., 2016). Most of these experiments suggest a positive role of biochar on both the performance and the quality of the end product of the process. Thus far, however, such trials have been performed only at small or medium scale.

\section{Conclusions}

Composting is a process highly valued in waste management owing to its robustness and the possibility of obtaining a valuable product with soil amendment potential. The composting operational conditions and the conditioning of the raw materials have been widely studied, as seen in the scientific literature. However, new technologies have led to increased study on microbial succession and its impact on the quality of the final compost. Moreover, the assessment of gaseous emissions is of great relevance for ensuring the sustainability of the composting process.

Supplementary information for this review is on-line available.

\section{Acknowledgements}

The authors thank the Spanish Ministerio de Economía y Competitividad (Project CTM2015-69513R) for providing financial support. 
1. Abujabhah, I., Bound, S., Doyle, R., Bowman, J. 2016. Effects of biochar and compost amendments on soil physico-chemical properties and the total community within a temperate agricultural soil. Applied Soil Ecology, 98, 243-253.

2. Adhikari, B., Barrington, S., Martinez, J., King, S. 2008. Characterization of food waste and bulking agents for composting. Waste Management, 28(5), 795-804.

3. Agegnehu, G., Bass, A., Nelson, P., Bird, M. 2016. Benefits of biochar, compost and biochar-compost for soil quality, maize yield and greenhouse gas emissions in a tropical agricultural soil. Science of The Total Environment, 543, Part A, 295306.

4. Amir, S., Abouelwafa, R., Meddich, A., Souabi, S., Winterton, P., Merlina, G., Revel, J., Pinelli, E., Hafidi, M. 2010. PLFAs of the microbial communities in composting mixtures of agro-industry sludge with different proportions of household waste. International Biodeterioration \& Biodegradation, 64(7), 614-621.

5. Antunes, L., Martins, L., Pereira, R., Thomas, A., Barbosa, D., Lemos, L., Silva, G., Moura, L., Epamino, G., Digiampietri, L., Lombardi, K., Ramos, P., Quaggio, R., de Oliveira, J., Pascon, R., Cruz, J., da Silva, A., Setubal, J. 2016. Microbial community structure and dynamics in thermophilic composting viewed through metagenomics and metatranscriptomics. Scientific Reports, 6, 38915.

6. Barrena, R., d'Imporzano, G., Ponsa, S., Gea, T., Artola, A., Vazquez, F., Sanchez, A., Adani, F. 2009. In search of a reliable technique for the determination of the biological stability of the organic matter in the mechanical-biological treated waste. J Hazard Mater, 162(2-3), 1065-72.

7. Barrena, R., Vázquez, F., Sánchez, A. 2006. The use of respiration indices in the composting process: a review. Waste Management \& Research, 24(1), 37-47.

8. Bent, S., Forney, J. 2008. The tragedy of the uncommon: understanding limitations in the analysis of microbial diversity. ISME J, 2(7), 689-695.

9. Bernstad, A., Wenzel, H., la Cour Jansen, J. 2016. Identification of decisive factors for greenhouse gas emissions in comparative life cycle assessments of food waste management - an analytical review. Journal of Cleaner Production, 119, 13-24.

10. Bielská, L., Kah, M., Sigmund, G., Hofmann, T., Höss, S. 2017. Bioavailability and toxicity of pyrene in soils upon biochar and compost addition. Science of The Total Environment, 595, 132-140.

11. Boldrin, A., Andersen, J., Moller, J., Christensen, T., Favoino, E. 2009. Composting and compost utilization: accounting of greenhouse gases and global warming contributions. Waste Manag Res, 27(8), 800-12.

12. Borrero, C., Ordovás, J., Trillas, M.I., Avilés, M. 2006. Tomato Fusarium wilt suppressiveness. The relationship between the organic plant growth media and their microbial communities as characterised by Biolog $®$. Soil Biology and Biochemistry, 38(7), 1631-1637.

13. Carpenter-Boggs, L., Kennedy, A., Reganold, J. 1998. Use of Phospholipid Fatty Acids and Carbon Source Utilization Patterns To Track Microbial Community Succession in Developing Compost. Applied and Environmental Microbiology, 64(10), 4062-4064.

14. Colon, J., Cadena, E., Pognani, M., Barrena, R., Sanchez, A., Font, X., Artola, A. 2012. Determination of the energy and environmental burdens associated with the biological treatment of source-separated Municipal Solid Wastes. Energy \& Environmental Science, 5(2), 5731-5741. 
15. Colon, J., Ponsá, S., Álvarez, C., Vinot, M., Lafuente, F., Gabriel, D., Sánchez, A. 2017. Analysis of MSW full scale facilities based on anaerobic digestion and/or composting using respiration indices as performance indicators. Bioresource Technology, 236, 87-96.

16. Chandna, P., Nain, L., Singh, S., Kuhad, R. 2013. Assessment of bacterial diversity during composting of agricultural by products. BMC Microbiology, 13(1), 99.

17. Chang, J., Hsu, T. 2008. Effect of compositions on food waste composting. Bioresource Technology, 99(17), 8068-8074.

18. de Vries, W., Groenenberg, J., Lofts, S., Tipping, E., Posch, M. 2013. Critical Loads of Heavy Metals for Soils. in: Heavy Metals in Soils: Trace Metals and Metalloids in Soils and their Bioavailability, (Ed.) B.J. Alloway, Springer Netherlands. Dordrecht, pp. 211-237.

19. Ding, J., Hao, Y., Hou, J., Liu, D., Xi, B., Li, M., Wu, M. 2016. Effects of antiacidification microbial agents (AAMA) on reducing acidification and promoting humification during kitchen waste composting. Research of Environmental Sciences, 29, 1887-1894.

20. Fan, Y., Lee, C., Klemeš, J., Chua, L., Sarmidi, M., Leow, C. 2017. Evaluation of Effective Microorganisms on home scale organic waste composting. Journal of Environmental Management. Available on-line: doi: 10.1016/j.jenvman.2017.04.019.

21. Fernandez-Delgado Juarez, M., Prahauser, B., Walter, A., Insam, H., FrankeWhittle, I. 2015. Co-composting of biowaste and wood ash, influence on a microbially driven-process. Waste Management, 46, 155-64.

22. Franke-Whittle, I., Confalonieri, A., Insam, H., Schlegelmilch, M., Körner, I. 2014. Changes in the microbial communities during co-composting of digestates. Waste Management, 34(3), 632-641.

23. Franke-Whittle, I.H., Klammer, S.H., Insam, H. 2005. Design and application of an oligonucleotide microarray for the investigation of compost microbial communities. Journal of Microbiological Methods, 62(1), 37-56.

24. García-Jaramillo, M., Cox, L., Cornejo, J., Hermosín, M. 2014. Effect of soil organic amendments on the behavior of bentazone and tricyclazole. Science of The Total Environment, 466-467, 906-913.

25. Gomes, N., Landi, L., Smalla, K., Nannipieri, P., Brookes, P., Renella, G. 2010. Effects of Cd- and Zn-enriched sewage sludge on soil bacterial and fungal communities. Ecotoxicology and Environmental Safety, 73(6), 1255-1263.

26. Guo, R., Li, G., Jiang, T., Schuchardt, F., Chen, T., Zhao, Y., Shen, Y. 2012. Effect of aeration rate, $\mathrm{C} / \mathrm{N}$ ratio and moisture content on the stability and maturity of compost. Bioresource Technology, 112, 171-178.

27. Hargreaves, J., Adl, M., Warman, P. 2008. A review of the use of composted municipal solid waste in agriculture. Agriculture, Ecosystems \& Environment, 123(1-3), 1-14.

28. He, X., Logan, S., Traina, S. 1995. Physical and chemical characteristics of selected U.S. municipal solid waste composts. Journal of Environmental Quality, 24, 543552.

29. Hong, G., El Hady, B., Joo, K., Shin, D. 2012. Characterization of moisture and free air space effects and the optimal operation of a composting process for minimal waste and energy use. in: Computer Aided Chemical Engineering, (Eds.) A. Iftekhar, S. Rajagopalan, Vol. Volume 31, Elsevier, pp. 500-504. 
30. Horiuchi, J., Ebie, K., Tada, K., Kobayashi, M., Kanno, T. 2003. Simplified method for estimation of microbial activity in compost by ATP analysis. Bioresource Technology, 86(1), 95-8.

31. Hou, N., Wen, L., Cao, H., Liu, K., An, X., Li, D., Wang, H., Du, X., Li, C. 2017. Role of psychrotrophic bacteria in organic domestic waste composting in cold regions of China. Bioresource Technology, 236, 20-28.

32. Huerta-Pujol, O., Gallart, M., Soliva, M., Martínez-Farré, F., López, M. 2011. Effect of collection system on mineral content of biowaste. Resources, Conservation and Recycling, 55(11), 1095-1099.

33. Huerta-Pujol, O., Soliva, M., Giró, F., López, M. 2010. Heavy metal content in rubbish bags used for separate collection of biowaste. Waste Management, 30(8-9), 1450-1456.

34. IPCC. 2006. Waste generation, compositions and management data. Guidelines for national greenhouse gas inventories. Intergovernmental Panel on Climate Change. WMO/UNEP.

35. Ishii, K., Takii, S. 2003. Comparison of microbial communities in four different composting processes as evaluated by denaturing gradient gel electrophoresis analysis. J Appl Microbiol, 95(1), 109-19.

36. Jurado, M., López, M., Suárez-Estrella, F., Vargas-García, M., López-González, J., Moreno, J. 2014. Exploiting composting biodiversity: Study of the persistent and biotechnologically relevant microorganisms from lignocellulose-based composting. Bioresource Technology, 162, 283-293.

37. Karnchanawong, S., Nissaikla, S. 2014. Effects of microbial inoculation on composting of household organic waste using passive aeration bin. International Journal of Recycling of Organic Waste in Agriculture, 3(4), 113-119.

38. Ke, G., Lai, C., Liu, Y., Yang, S. 2010. Inoculation of food waste with the thermotolerant lipolytic actinomycete Thermoactinomyces vulgaris A31 and maturity evaluation of the compost. Bioresource Technology, 101(19), 7424-7431.

39. Khan, N., Clark, I., Sánchez-Monedero, M., Shea, S., Meier, S., Qi, F., Kookana, R., Bolan, N. 2016. Physical and chemical properties of biochars co-composted with biowastes and incubated with a chicken litter compost. Chemosphere, 142, 1423.

40. Kinet, R., Destain, J., Hiligsmann, S., Thonart, P., Delhalle, L., Taminiau, B., Daube, G., Delvigne, F. 2015. Thermophilic and cellulolytic consortium isolated from composting plants improves anaerobic digestion of cellulosic biomass: Toward a microbial resource management approach. Bioresource Technology, 189, 138-144.

41. Komilis, D., Ham, R., Park, J. 2004. Emission of volatile organic compounds during composting of municipal solid wastes. Water Research, 38(7), 1707-1714.

42. Komilis, D., Kletsas, C. 2012. Static respiration indices to investigate compost stability: effect of sample weight and temperature and comparison with dynamic respiration indices. Bioresource Technology, 121, 467-70.

43. Komilis, D., Kontou, I., Ntougias, S. 2011. A modified static respiration assay and its relationship with an enzymatic test to assess compost stability and maturity. Bioresource Technology, 102(10), 5863-5872.

44. Komilis, D., Tziouvaras, I. 2009. A statistical analysis to assess the maturity and stability of six composts. Waste Management, 29(5), 1504-1513.

45. Külcü, R. 2015. Determination of the relationship between FAS values and energy consumption in the composting process. Ecological Engineering, 81, 444-450. 
46. Kuppusami, S., Thavamani, P., Venkaterwarlu, K., Lee, Y., Naidu, R., Megharaj, M. 2017. Remediation approaches for polycyclic aromatic carbons (PAHs) contaminated soils: Technological constraints, emerging trends and future directions. Chemosphere; 168, 944-968.

47. Lehmann, J., Joseph, S. 2009. Biochar for Environmental Management: Science and Technology. Earthscan Publishing for a sustainable future, London.

48. Li, Z., Huang, G., Yu, H., Zhou, Y., Huang, W. 2015. Critical factors and their effects on product maturity in food waste composting. Environmental Monitoring and Assessment, 187(4), 217.

49. Li, Z., Lu, H., Ren, L., He, L. 2013. Experimental and modeling approaches for food waste composting: A review. Chemosphere, 93(7), 1247-1257.

50. Liwarska-Bizukojc, E., Ledakowicz, S. 2003. Stoichiometry of the aerobic biodegradation of the organic fraction of municipal solid waste (MSW). Biodegradation, 14, 51-56.

51. López-González, J., Vargas-García, M., López, M., Suárez-Estrella, F., Jurado, M., Moreno, J. 2015. Biodiversity and succession of mycobiota associated to agricultural lignocellulosic waste-based composting. Bioresource Technology, 187, 305-313.

52. Lou, X., Nair, J. 2009. The impact of landfilling and composting on greenhouse gas emissions - A review. Bioresource Technology, 100(16), 3792-3798.

53. Manu, M.K., Kumar, R., Garg, A. 2017. Performance assessment of improved composting system for food waste with varying aeration and use of microbial inoculum. Bioresource Technology, 234, 167-177.

54. Martínez-Blanco, J., Lazcano, C., Christensen, T.H., Muñoz, P., Rieradevall, J., Møller, J., Antón, A., Boldrin, A. 2013. Compost benefits for agriculture evaluated by life cycle assessment. A review. Agronomy for Sustainable Development, 33(4), 721-732.

55. Maulini-Duran, C., Artola, A., Font, X., Sanchez, A. 2014. Gaseous emissions in municipal wastes composting: effect of the bulking agent. Bioresource Technology, 172, 260-8.

56. Morillo, E., Villaverde, J. 2017. Advanced technologies for the remediation of pesticide-contaminated soils. Science of The Total Environment, 586, 576-597.

57. Mu, D., Horowitz, N., Casey, M., Jones, K. 2017. Environmental and economic analysis of an in-vessel food waste composting system at Kean University in the U.S. Waste Management, 59, 476-486.

58. Nair, J., Okamitsu, K. 2010. Microbial inoculants for small scale composting of putrescible kitchen wastes. Waste Management, 30(6), 977-82.

59. Nakasaki, K., Hirai, H. 2017. Temperature control strategy to enhance the activity of yeast inoculated into compost raw material for accelerated composting. Waste Management. Available on-line: doi: 10.1016/j.wasman.2017.04.019.

60. Nasini, L., De Luca, G., Ricci, A., Ortolani, F., Caselli, A., Massaccesi, L., Regni, L., Gigliotti, G., Proietti, P. 2016. Gas emissions during olive mill waste composting under static pile conditions. International Biodeterioration \& Biodegradation, 107, 70-76.

61. Onwosi, C., Igbokwe, V., Odimba, J., Eke, I., Nwankwoala, M., Iroh, I., Ezeogu, L. 2017. Composting technology in waste stabilization: On the methods, challenges and future prospects. Journal of Environmental Management, 190, 140-157.

62. Oviedo-Ocaña, E., Torres-Lozada, P., Marmolejo-Rebellon, L., Hoyos, L., Gonzales, S., Barrena, R., Komilis, D., Sanchez, A. 2015. Stability and maturity of 
biowaste composts derived by small municipalities: Correlation among physical, chemical and biological indices. Waste Management, 44, 63-71.

63. Pagans, E., Barrena, R., Font, X., Sánchez, A. 2006. Ammonia emissions from the composting of different organic wastes. Dependency on process temperature. Chemosphere, 62(9), 1534-1542.

64. Pierucci, P., Porazzi, E., Martinez, M., Adani, F., Carati, C., Rubino, F., Colombi, A., Calcaterra, E., Benfenati, E. 2005. Volatile organic compounds produced during the aerobic biological processing of municipal solid waste in a pilot plant. Chemosphere, 59(3), 423-430.

65. Puig-Ventosa, I., Freire-González, J., Jofra-Sora, M. 2013. Determining factors for the presence of impurities in selectively collected biowaste. Waste Management \& Research, 31, 510-517.

66. Puyuelo, B., Gea, T., Sánchez, A. 2010. A new control strategy for the composting process based on the oxygen uptake rate. Chemical Engineering Journal, 165(1), 161-169.

67. Puyuelo, B., Ponsá, S., Gea, T., Sánchez, A. 2011. Determining C/N ratios for typical organic wastes using biodegradable fractions. Chemosphere, 85(4), 653659.

68. Rasapoor, M., Adl, M., Pourazizi, B. 2016. Comparative evaluation of aeration methods for municipal solid waste composting from the perspective of resource management: A practical case study in Tehran, Iran. Journal of Environmental Management, 184(3), 528-534.

69. Ruggieri, L., Gea, T., Artola, A., Sanchez, A. 2009. Air filled porosity measurements by air pycnometry in the composting process: a review and a correlation analysis. Bioresource Technology, 100(10), 2655-66.

70. Ryckeboer, J., Mergaert, J., Coosemans, J., Deprins, K., Swings, J. 2003. Microbiological aspects of biowaste during composting in a monitored compost bin. Journal of Applied Microbiology, 94(1), 127-137.

71. Safaei Khorram, M., Zhang, Q., Lin, D., Zheng, Y., Fang, H., Yu, Y. 2016. Biochar: A review of its impact on pesticide behavior in soil environments and its potential applications. Journal of Environmental Sciences, 44, 269-279.

72. Sax, M., Bassuk, N., van Es, H., Rakow, D. 2017. Long-Term Remediation of Compacted Urban Soils by Physical Fracturing and Incorporation of Compost. Urban Forestry \& Urban Greening. Available on line: 10.1016/j.ufug.2017.03.023

73. Scaglia, B., Orzi, V., Artola, A., Font, X., Davoli, E., Sanchez, A., Adani, F. 2011. Odours and volatile organic compounds emitted from municipal solid waste at different stage of decomposition and relationship with biological stability. Bioresource Technology, 102(7), 4638-4645.

74. Schwalb, M., Rosevear, C., Chin, R., Barrington, S. 2011. Food waste treatment in a community center. Waste Management, 31(7), 1570-1575.

75. Sharifi, Z., Renella, G. 2015. Assessment of a particle size fractionation as a technology for reducing heavy metal, salinity and impurities from compost produced by municipal solid waste. Waste Management, 38, 95-101.

76. Shi, S., Zou, D., Wang, Q., Xia, X., Zheng, T., Wu, C., Gao, M. 2016. Responses of ammonia-oxidizing bacteria community composition to temporal changes in physicochemical parameters during food waste composting. RSC Advances, 6, 9541-9548.

77. Soares, M., Quina, M., Quinta-Ferreira, R. 2013. Prediction of free air space in initial composting mixtures by a statistical design approach. Journal of Environmental Management, 128, 75-82. 
78. Su, D., McCartney, D., Wang, Q. 2006. Comparison of Free Air Space Test Methods. Compost Science \& Utilization, 14(2), 103-113.

79. Sundberg, C., Yu, D., Franke-Whittle, I., Kauppi, S., Smårs, S., Insam, H., Romantschuk, M., Jönsson, H. 2013. Effects of $\mathrm{pH}$ and microbial composition on odour in food waste composting. Waste Management, 33(1), 204-211.

80. Thi, N., Kumar, G., Lin, C. 2015. An overview of food waste management in developing countries: Current status and future perspective. Journal of Environmental Management, 157, 220-229.

81. Tiquia, S. 2010. Using terminal restriction fragment length polymorphism (TRFLP) analysis to assess microbial community structure in compost systems. Methods Mol Biol, 599, 89-102.

82. Troschinetz, A.M., Mihelcic, J.R. 2009. Sustainable recycling of municipal solid waste in developing countries Waste Management, 29(2), 915-923.

83. Tsai, C., Chen, M., Ye, A., Chou, M., Shen, S., Mao, I. 2008. The relationship of odor concentration and the critical components emitted from food waste composting plants. Atmospheric Environment, 42(35), 8246-8251.

84. Tsai, S., Liu, C., Yang, S. 2007. Microbial conversion of food wastes for biofertilizer production with thermophilic lipolytic microbes. Renewable Energy, 32(6), 904-915.

85. Vandecasteele, B., Sinicco, T., D'Hose, T., Vanden Nest, T., Mondini, C. 2016. Biochar amendment before or after composting affects compost quality and $\mathrm{N}$ losses, but not P plant uptake. Journal of Environmental Management, 168, 200209.

86. Vargas-García, M., Suárez-Estrella, F., López, M., Moreno, J. 2010. Microbial population dynamics and enzyme activities in composting processes with different starting materials. Waste Management, 30(5), 771-778.

87. Wang, X., Wen, W., Pan, S., Lin, X., Chen, S. 2016. Influence of conditioner proportion on aerobic composting of food waste and microbial characteristics. Chinese Journal of Environmental Engineering, 10(6), 3215-3222.

88. Wang, X., Pan, S., Zhang, Z., Lin, X., Zhang, Y., Chen, S. 2017. Effects of the feeding ratio of food waste on fed-batch aerobic composting and its microbial community. Bioresource Technology, 224, 397-404.

89. Wei, Y., Li, J., Shi, D., Liu, G., Zhao, Y., Shimaoka, T. 2017. Environmental challenges impeding the composting of biodegradable municipal solid waste: A critical review. Resources, Conservation and Recycling, 122, 51-65.

90. Xie, X., Zhao, Y., Sun, Q., Wang, X., Cui, H., Zhang, X., Li, Y., Wei, Z. 2017. A Novel Method for Contributing to Composting Start-up at Low Temperature by Inoculating Cold-adapted Microbial Consortium. Bioresource Technology, 238, 3947.

91. Young, B., Rizzo, P., Riera, N., Torre, V., López, V., Molina, C., Fernández, F., Crespo, D., Barrena, R., Komilis, D., Sánchez, A. 2016. Development of phytotoxicity indexes and their correlation with ecotoxicological, stability and physicochemical parameters during passive composting of poultry manure. Waste Management, 54, 101-109.

92. Yu, S., Grant Clark, O., Leonard, J. 2009. Influence of free air space on microbial kinetics in passively aerated compost. Bioresource Technology, 100(2), 782-790.

93. Yuan, J., Yang, Q., Zhang, Z., Li, G., Luo, W., Zhang, D. 2015. Use of additive and pretreatment to control odors in municipal kitchen waste during aerobic composting. Journal of Environmental Sciences, 37, 83-90. 
1019

1020

1021

1022

1023

1024

1025

1026

1027

1028

1029

1030

94. Yuan, Y., Tao, Y., Zhou, S., Yuan, T., Lu, Q., He, J. 2012. Electron transfer capacity as a rapid and simple maturity index for compost. Bioresource Technology, 116, 428-434.

95. Zang, B., Shuyan, L., Michel, F., Li, G., Luo, Y., Zhang, D., Li, Y. 2016. Effects of mix ratio, moisture content and aeration rate on sulfur odor emissions during pig manure composting. Waste Management; 56, 498-505.

96. Zeng, G., Yu, M., Chen, Y., Huang, D., Zhang, J., Huang, H., Jiang, R., Yu, Z. 2010. Effects of inoculation with Phanerochaete chrysosporium at various time points on enzyme activities during agricultural waste composting. Bioresource Technology, 101(1), 222-227.

97. Zhang, H., Li, G., Gu, J., Wang, G., Li, Y., Zhang, D. 2016. Influence of aeration on volatile sulfur compounds (VSCs) and NH3 emissions during aerobic composting of kitchen waste. Waste Management, 58, 369-375.

98. Zhang, L., Sun, X. 2016. Improving green waste composting by addition of sugarcane bagasse and exhausted grape marc. Bioresource Technology, 218, 33543.

99. Zhao, Y., Lu, Q., Wei, Y., Cui, H., Zhang, X., Wang, X., Shan, S., Wei, Z. 2016. Effect of actinobacteria agent inoculation methods on cellulose degradation during composting based on redundancy analysis. Bioresource Technology, 219, 196-203. 100.Zhou, R., Liu, X., Luo, L., Zhou, Y., Wei, J., Chen, A., Tang, L., Wu, H., Deng, Y., Zhang, F., Wang, Y. 2017. Remediation of $\mathrm{Cu}, \mathrm{Pb}, \mathrm{Zn}$ and Cd-contaminated agricultural soil using a combined red mud and compost amendment. International Biodeterioration \& Biodegradation, 118, 73-81. 


\section{Figures}

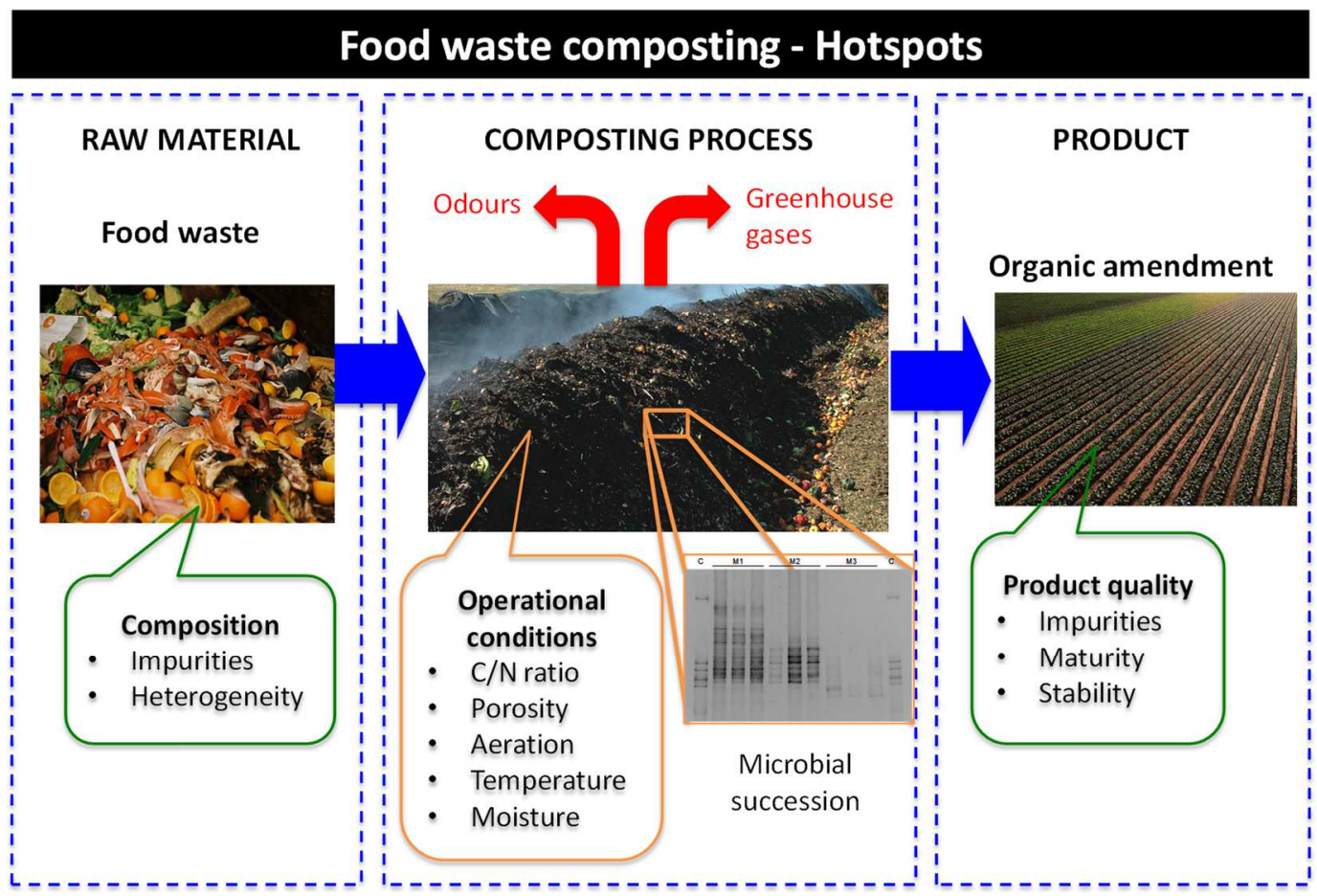

1034

1035 Figure 1. Hotspots of research regarding food waste composting. 


\section{Tables}

Table 1. Summary of some microorganisms detected in different stages of the composting process

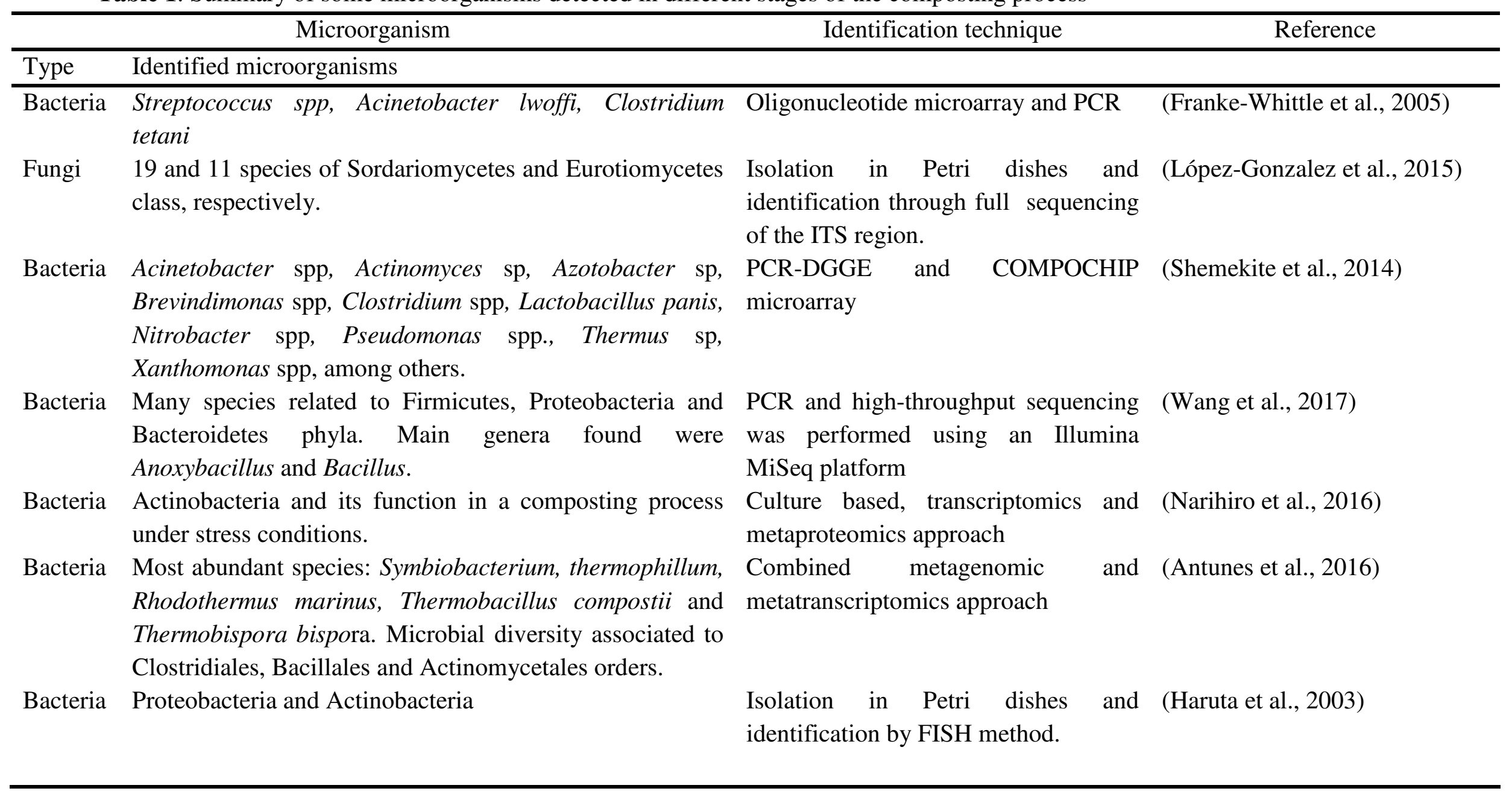


Table 1. (continuation)

\begin{tabular}{|c|c|c|c|}
\hline & Microorganism & Identification technique & Reference \\
\hline Type & Identified microorganisms & & \\
\hline Fungi & $\begin{array}{l}\text { The most abundant genera obtained were Saccharomyces, } \\
\text { Candida and Schizosaccharomyces. }\end{array}$ & Metaproteomics & (Liu et al., 2015) \\
\hline Bacteria & $\begin{array}{l}\text { The most abundant microbial population obtained from } \\
\text { the Gammaproteobacteria class: Pseudomonadales and } \\
\text { Enterobacteriales orders. From the Bacilli class: Bacillales } \\
\text { and Lactobacillales orders and from the Actinobacteria } \\
\text { class: Corynebacterinae order. }\end{array}$ & Metaproteomics & (Liu et al., 2015) \\
\hline Bacteria & $\begin{array}{l}\text { Proteobacteria, Firmicutes, Chloroflexi, Actinobacteria } \\
\text { and Bacteroidetes. Also a minor presence of Deinococcus, } \\
\text { Thermus, Verrucomicrobia,TM7, Planctomycetes and } \\
\text { Acidobacteria. }\end{array}$ & Clone library from $16 \mathrm{~S}$ rRNA & (Tian et al., 2013) \\
\hline
\end{tabular}


Table 2. Maturity indices used to assess food waste compost maturity.

\begin{tabular}{|c|c|c|}
\hline Parameter & Findings & Reference \\
\hline Nitrification index & $\begin{array}{l}\mathrm{NI}<0.5, \text { fully mature } \\
0.5<\mathrm{NI}<3 \text {, mature } \\
\mathrm{NI}>3 \text {, immature }\end{array}$ & $\begin{array}{l}\text { (Zhang and Sun, } \\
\text { 2016), } \\
\text { (Fernandez-Delgado } \\
\text { Juarez et al., 2015) }\end{array}$ \\
\hline Germination index & $\begin{array}{l}\text { Sensitive indicator for maturation and } \\
\text { phytotoxicity }\end{array}$ & (Guo et al., 2012) \\
\hline $\begin{array}{l}\text { Dissolved organic } \\
\text { matter and electron } \\
\text { transfer capacity } \\
\text { (ETC) }\end{array}$ & $\begin{array}{l}\text {-Decomposition degree is associated } \\
\text { with dissolved organic matter. } \\
\text {-ETC correlated with germination } \\
\text { index. }\end{array}$ & (Yuan et al., 2012) \\
\hline Particle size & $\begin{array}{l}\text { Optimum size for mature compost: } \\
0.25-2.0 \mathrm{~mm}\end{array}$ & $\begin{array}{l}\text { (Zhang and Sun, } \\
\text { 2016) }\end{array}$ \\
\hline $\begin{array}{l}\text { Polymerisation } \\
\text { degree }\end{array}$ & $\begin{array}{l}\text { - Formation of simple sugars } \\
\text {-Reduction of non-humic substances }\end{array}$ & $\begin{array}{l}\text { (Zhang and Sun, } \\
\text { 2016) }\end{array}$ \\
\hline $\begin{array}{l}\text { Fluroscein diacetate } \\
\text { enzymatic assay }\end{array}$ & $\begin{array}{l}\text { Correlated marginally with the } \\
\text { germination index }\end{array}$ & (Komilis et al., 2011) \\
\hline $\begin{array}{l}\text { Phytotoxicity index } \\
\left(\mathrm{GIC}_{80 \%} \text { and }\right.\end{array}$ & $\begin{array}{l}\text { Values below } 100 \% \text { indicate immaturity } \\
\text { or any toxicity degree. }\end{array}$ & (Young et al., 2016) \\
\hline $\left.\mathrm{RGIC}_{0.8}\right)$ & $\begin{array}{l}\text { Values above } 100 \% \text { indicate maturity } \\
\text { and no toxicity. }\end{array}$ & \\
\hline
\end{tabular}

